\title{
Mobile APPs and Global Markets
}

\author{
Kungpo Tao, Paulette Edmunds \\ Department of Business and Economics, Elizabeth City State University, Elizabeth City, USA \\ Email: ktao@ecsu.edu, pkedmunds@ecsu.edu
}

How to cite this paper: Tao, K. and Edmunds, P. (2018) Mobile APPs and Global Markets. Theoretical Economics Letters, 8, 1510-1524.

https://doi.org/10.4236/tel.2018.88097

Received: March 1, 2018

Accepted: June 9, 2018

Published: June 12, 2018

Copyright (c) 2018 by authors and Scientific Research Publishing Inc. This work is licensed under the Creative Commons Attribution International License (CC BY 4.0).

http://creativecommons.org/licenses/by/4.0/

\section{(c) () Open Access}

\begin{abstract}
In this research, we examine the popularity of mobile applications across different categories by using the measures of monthly active users (MAUs) of each app. It is the authors' intention to inspect the key characteristics of mobile apps and the relationship those characteristics have with market share and growth rate in global markets. The ease of use of mobile apps leads to a subsequent impact on the global users' mobile behavior in daily life. Mobile apps have flooded the market, however, the acceptance and use of individual apps relies on a combination of the preference of users and the operational strategies employed by app developers. Based on secondary data collected from multiple sources including both publications and online data, the global market growth of mobile apps including China (the world's largest market of mobile apps) has shown a correlation between apps' market share and the users' mobile behavior based on messaging, networking, shopping, video watching, and gaming. This research categorizes users' mobile behavior in terms of age groups and time spent on certain mobile apps. The objective of this investigation is better understanding of the dominance of leading mobile apps and the future trend of mobile apps designed for the global market.
\end{abstract}

\section{Keywords}

Mobile Apps, Monthly Active Users (MAUs), Global Markets, Messaging Apps, Social Network Apps

\section{Introduction}

The number of smartphone users worldwide has reached 2.5 billion, which is equivalent to $33 \%$ of the world population. The annual $10 \%$ growth rate of smartphone users since 2014 has triggered the fast growth of mobile applications (apps). Taylor [1] defines mobile apps as "small programs that run on a mobile device and perform tasks ranging from banking to gaming and web browsing". The proliferation of mobile apps has led to a dramatic increase in app use by 
global smart phone consumers. By their ease of use, mobile apps have become popular everywhere in the world. There were almost 200 billion mobile apps downloads in 2017, up 32\% from a year earlier.

Compatibility with mobile devices is no longer an issue because most apps have versions for both iOS and android operating systems. Any user of a smartphone or tablet is able to choose mobile apps specifically designed for their device and install the apps without difficulty. Mobile apps are powerful tools that allow users to perform social tasks including making calls and texting, additionally, apps provide job-related and personal services. Mobile apps provide a wide range of functions including stock market activities, banking, spreadsheet calculations, and GPS navigation. Furthermore, mobile apps can be customized to focus on many of the user's specific requirements. Consequently, mobile apps have become necessary for users in addressing daily life activities.

The phenomenon of employing mobile apps has expanded globally. Worldwide, apps users are spending more of their mobile minutes with apps than they are with web browsers. Compared to the traditional format of Internet operations, mobile apps have surpassed website-based services in usage. Gupta [2] states that on an average, users spent $82 \%$ of their mobile minutes with apps and just $18 \%$ of their mobile minutes with web browsers. Key characteristics of mobile apps that make them desirable are mobility, uniqueness, and speed.

Mobile apps make it possible for users to interact with other users anytime and anywhere [3]. Social networking apps have experienced a rapid expansion in users around the world. These mobile apps support information sharing and interacting opportunities. They also provide a new platform for obtaining news. According to the report of social media statistics from Statista [4], the number of social mobile apps users is projected to reach 2.9 billion by the end of 2018 . Among all social networking platforms, Facebook is the leading app in terms of number of monthly active users (MAUs) with 1.6 billion MAUs around the world. Following behind in MAUs is WeChat [excluding instant messenger apps such as WhatsApp and QQ [5]. MAUs are the most common measure of mobile app usage since there are numerous types of mobile apps and the users' stickiness varies [6].

The study finds that the presence of in app ads does not negatively affect the popularity of mobile apps. This knowledge is beneficial to both mobile app developers and marketers. Developers can accept in app ads to cover the cost of developing and maintaining the apps without concern of pushback from users. Furthermore, mobile apps provide marketers with a medium that allows them to connect with their target market. Mobile apps that enjoy significant global market share are those that make the purchase process generated by in app ads uncomplicated and seamless. Apps have a competitive advantage when they are associated with a popular brand, are easy to recognize, have language support, and allow video streaming. There are barriers to unlimited mobile app growth. Some countries, such as China, make it difficult, if not impossible, for its citizens 
to access non-nationally owned apps.

A limitation of the study is the reliance on secondary data. Data collected for a purpose other than the current research may not contain all the information desired. Additionally, the reliability and validity of secondary data is not always confirmable. This is especially true with data coming from international sources where the government maintains strict control over what information is available.

Organization of the paper begins with a background of mobile apps status and the global market leading to the research questions and objectives. Next is a discussion of the research methodology, proposed hypotheses, and presentation of the results. Following the results are the managerial implications of the findings and the conclusions.

\section{Research Questions}

There were more than 2 million apps available from both the Apple Store and Google Play in 2017 [7]. Mobile app developers provide the option of free or low cost apps for users to download and install on their smartphones. While there are countless numbers of apps available, a relatively small number of mobile apps are popular and used regularly. In less than 10 years, the apps industry has evolved from merely mobile browsing of a web-based nature to integrating multiple functions into a single platform. Users enjoy the convenience and utility provided by informative apps and the fun derived from gaming apps, but now they have come to expect more. Essential apps that deliver maps, weather, and news are the most downloaded apps across all platforms. However, locating the appropriate app is challenging because many mobile app categories lack a clear definition and the boundaries between app classifications are hazy. Searching and selecting a mobile app by category could be problematic since category descriptions may not appear to match the needs and wants of an app user.

Two research questions are derived from the above discussion:

1) Do users mentally place mobile apps into differentiated categories, e.g., social networking, messaging, video streaming, and shopping?

2) Do the leading mobile apps in the global market adopt the appropriate marketing strategy to reach their customers?

\section{Research Objectives}

The global market of mobile apps has matured; however, new apps continue to enter the market. Smartphones became available in 2010. The number of smartphone users worldwide has reached 2.5 billion, which is equivalent to $33 \%$ of the world population [4]. After eight years of experience with smartphones, mobile app users are practiced at selecting and using products that meet their needs. According to Dogtiev [8], there were almost 200 billion mobile apps downloads in 2017, up $32 \%$ from 150 billion downloads in 2016. Switching to a new app is common when the user is not satisfied with the current mobile app even when 
the current app was just downloaded. Users quickly download, update, and keep the perceived best app and delete the apps they no longer consider relevant. This study aims to explore the status of mobile apps in the global market and to determine the factors influencing the dominance of the leading mobile apps.

The objectives of the study are as following:

1) In practice: The study focuses on market analysis and will assist mobile app developers in recognizing opportunities for entering the global market. Businesses will be able to discern trends in mobile app usage and see how mobile apps can assist them in improving service quality.

2) In academic: The study examines the behavior of mobile app users and provides researchers of global marketing with a foundation of consumer behavior related to mobile app usage around the world.

\section{Background}

Purcell [9] defined mobile apps as end-user software applications designed for a cell phone operating system to perform particular tasks. Based on that definition, smartphone performance and utility build on the use of mobile apps. Software makes the device valuable to users by providing interactive contents. Mobile apps were downloaded more than 90 billion times from inception through 2017; there were 200 million downloads in 2017 alone [10] [11]. The popularity of mobile apps and the development of an app global market, which includes China, the world's largest user of mobile apps [12], have contributed to the overall growth of mobile app usage.

\subsection{The Popularity of Mobile Apps}

Due to the fast development of Internet and mobile communication, smartphones have become the essential tool for modern people in meeting daily needs. In fact, mobile apps have changed users' lives by saving time and work effort. These conveniences have led to an increased demand for mobile apps. While users may have different reasons to use an app, the most common attributes sought are making life easier, clear instructions, appealing design, and consistence with multiple devices. According to an apps report from Google, most users expect apps to be free and their willingness to pay varies by category. When there is a charge for an app, the average price ranges from $\$ 1.49$ to $\$ 2.81$.

The growth and adoption rates of mobile apps are amazingly high. The rapid adoption of apps is attributed to their ease of use and the quick access to desired content [13]. However, not all mobile apps see activity. Smartphone owners make use of less than 10 apps every day [14]. Mobile apps providing services that enable users to easily complete daily tasks such as shopping, banking, mapping, browsing, and ordering food are used the most. The popularity of mobile apps has brought about a great opportunity for marketers to invest in ads and branding via mobile commerce channels [1].

Among the platforms for downloading, Apple Store and Google Play have 
dominated the market and they offer their own products for downloading as well offering independently designed apps. However, most of Apple Store and Google Play proprietary mobile apps are less popular than a number of the leading app products.

\subsection{International Mobile Apps Market}

The rapid growth of mobile apps usage is occurring around the world. The average time spent on mobile apps in the United States has reached 2 hours and 15 minutes per day [15]. South Korea, Brazil, and Mexico app usage has reached 3 hours [16]. Figure 1 shows that the users of mobile apps spent most of their time social networking, messaging, and video watching. Statista [17] declares that the region of the world with the highest penetration rate for social networks is North America, with $60 \%$ of the population having at least one social account. In the United States, the number is even higher, up to $78 \%$. Overall, global users spend 109 minutes per day on mobile apps.

Rather than using social network apps, Chinese users are more likely to use messaging apps to connect their social world. Statista [17] states that 650 million MAUs of social network apps are expected for China, which is almost a 30 million MAU increase since 2016. Overall, the users of social media apps have reached 1.15 billion in China. WeChat and QQ are the two dominating messaging apps in China, and they each have over 900 million MAUs. Both social networks have a primary target market of young people aged 16 to 29. QQ provides more activities and the platform is in transition from a pure messaging app into one that integrates multiple functions including chatting, gaming, music, and streaming. China is now the largest market of mobile apps in the world with revenues projected to be $\$ 42$ billion by 2020 [12]. The country will also record the most time spent on mobile apps. Chinese users spent roughly 225 billion hours in 2017 on mobile apps and that is more than 4.5 times greater than the

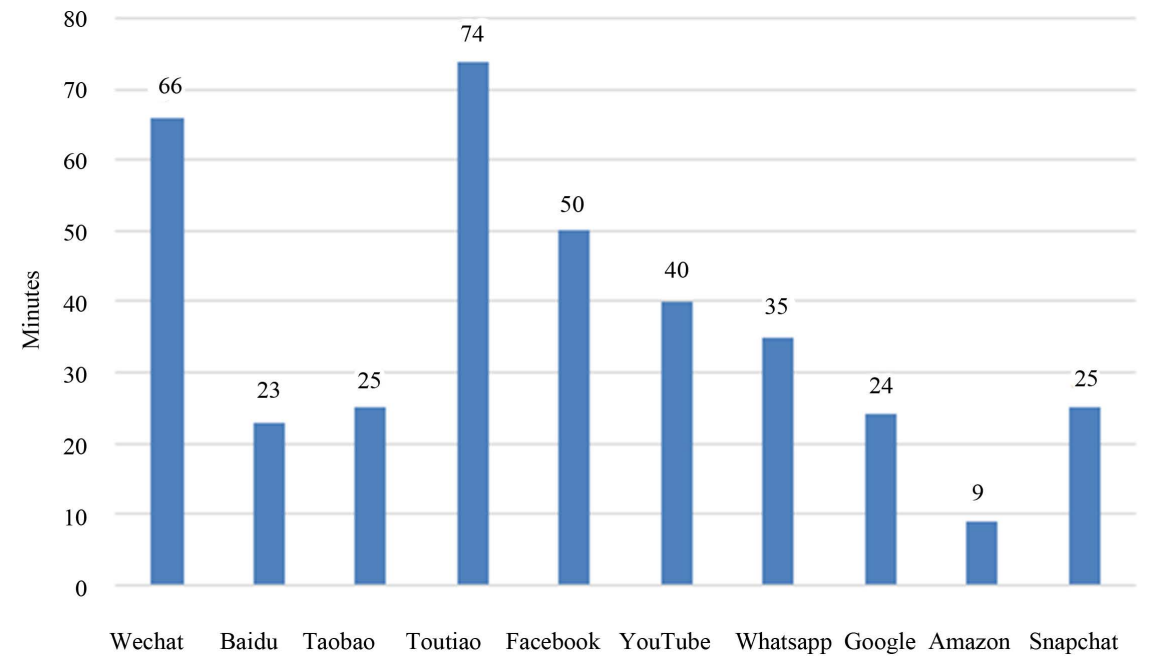

Figure 1. Average Time Spent on Mobile Apps per Day in 2017. Source: Tao [19]. 
second largest market of India [18]. As shown on Figure 1, Chinese users spent most of their time, 74 minutes, getting the news (Toutiao) and they spent 66 minutes messaging (WeChat).

Chinese users downloaded an average of 24 mobile apps; however, they spent most of their time on only 5 to 9 apps [20] [14]. Figure 2 shows the different time spent on mobile apps by category. App Annie [12] reports that $90 \%$ of Chinese users spent their time on mobile apps that are not dedicated to gaming. Instead, the Chinese focus on messaging apps (36\%). That contrasts with American users who are more likely to spend their time on social networking apps (22\%). Gaming apps have the biggest market in Japan and South Korea with 23\% and $19 \%$ time expenditure, respectively.

By adopting the model of technology acceptance, Gurtner [21] concluded that the ease of use is the most important factor influencing the intention of apps users. Results showed that young users of mobile apps are more interested in technological innovations and that age group paid particular attention to app performance. Middle age and elder users seek ease of use; possibly, because they did not grow up with smart phones as did the younger age group and it may take older smart phone users more effort to learn how to employ apps.

Figure 3 shows the percentage of different age groups using mobile apps. App users age 18 to 29 make up close to $50 \%$ of the users of the messaging app cluster including Sina Weibo, WhatsApp, and WeChat. The 18 to 49 age group heavily uses shopping apps. In China, the age group is $78 \%$ of the users of Taobao, an online marketplace, whereas Americans in that age group are $68 \%$ of all Amazon users.

\section{Methods}

Secondary data was collected through various third-party websites and reports dated from 2013 through 2017 because the global market of mobile apps has

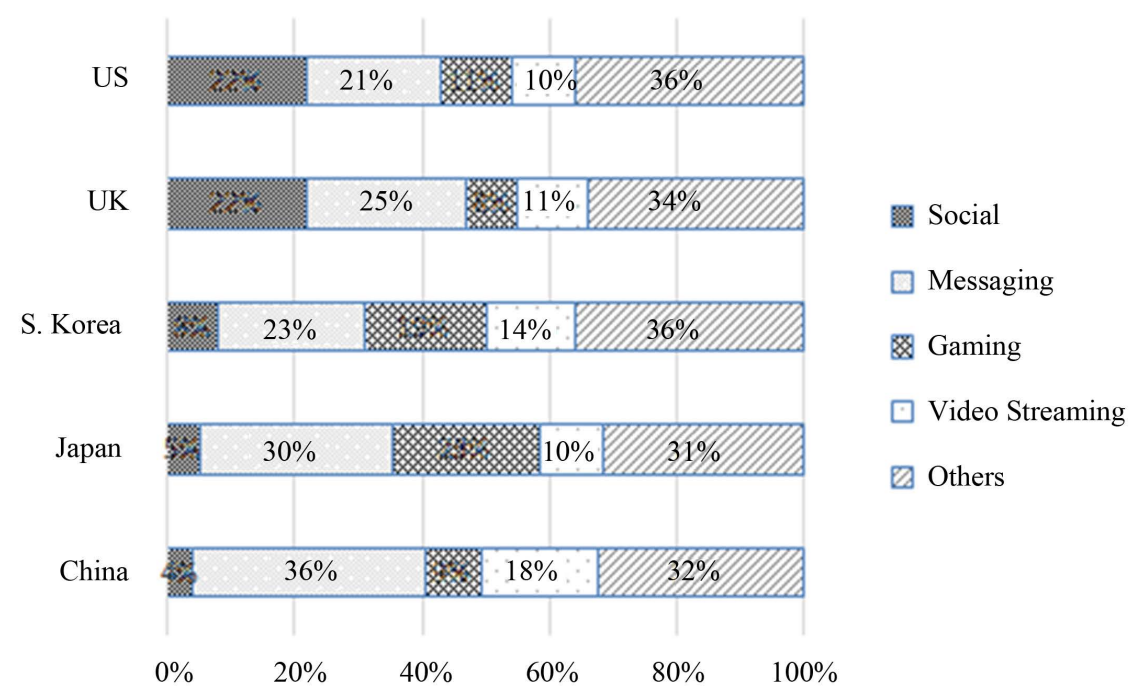

Figure 2. Time Spent on Mobile Apps by Category in 2017. Source: App Annie [12]. 


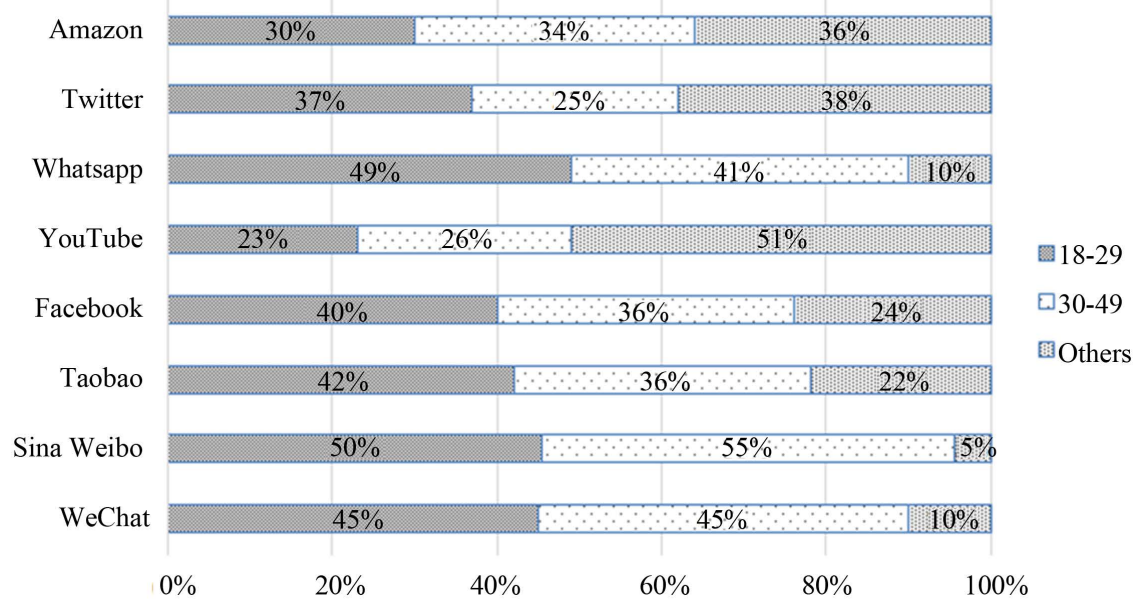

Figure 3. Age Range of Mobile App Users in 2017. Source: Tao [19].

grown dramatically over the recent five years. The number of downloading apps worldwide has even reached 50 billion since 2013 and the growth rate of more than $30 \%$ in recent three years has projected the market to reach the record highest by 2020 [22]. The data was gleaned from online statistics, market research, business intelligence, and journal publications. Both English and Chinese sources were checked to insure data quality.

Studies by Harris and Chin [23], Kulmeka [24], and Pon [25] confirmed the secondary data on mobile apps as being the best quality currently available. Among the most popular approaches, Google Play was deemed the primary data source to measure app market status [23] [24]. Pon [25] used the third party report of mobile phones' operation systems to examine the behavior. Additionally, mobile app downloading is considered quality data when actual app performance of users is essential and downloading is the only way to analyze the market information [26].

The mobile apps with top rankings and the highest growth rate in the United States, China, and world market were selected for the market analysis contained in this research. The list of leading mobile apps in the study was finalized based on Lella and Lipsman's [27] mobile apps report of the most popular mobile apps in the United States, App Annie's [28] report of the top mobile apps in the world, and Sampi's [29] report of the most popular mobile apps in China. The mobile apps' monthly active users, or MAUs, were adopted as the unit of measurement of stickiness. The concept and question of stickiness stems from the fact that it is common to see users experimenting by installing and uninstalling the same mobile app in a short period of time [6]. Therefore, MAUs is the best measure reflecting normal app usage because it represents the average number of mobile app users per month. Domestic market MAUs relative to the global market MAUs determined global market share of mobile apps usage. In total, 41 mobile apps were selected as the most popular in the world based on the secondary data collected. The mobile apps' attributes were recorded in a dichotomy 
format and the effect on market share was examined using t-tests. Among the 41 leading mobile apps, there are 8 paid apps (19\%), 26 apps with in-app ads (63\%), 5 apps with gaming (12\%), 14 apps with language support (34\%), 25 apps with video streaming (60\%), 31 apps with interaction (75\%), 20 apps with brand association (48\%), and 15 apps with digital purchase capability (36\%).

\section{Results}

\subsection{Messaging Apps}

By providing a solution to text message limits and associated costs, messaging app developers have won the war against the wireless providers. Messaging app users can now enjoy unlimited messaging and phone calls, and even make purchases while using apps. WhatsApp is the leading messaging app with 1.3 billion MAUs in the global market. Of the 187 countries in the world, WhatsApp, with the market share of 26\% (see Figure 4) is the leading messaging app in 109 countries [30]. Acquired by Facebook in 2014, WhatsApp is growing fast and has become one of the most popular apps worldwide due to its powerful function of social chatting and having no fees and no ads. Overall, the most two popular messaging apps-WhatsApp and Facebook messenger, with its $40 \%$ market share (See Figure 4), seem to be differentiated geographically. What intrigues the researchers is that Chinese users have their own messaging app called WeChat that has a market share of $22 \%$ (see Figure 4 ) and is the highest-ranking messaging app in China. Neither Facebook nor WhatsApp rank within the top 10 in the China market.

\subsection{Social Network Apps}

One of the most popular types of app, the social network app, comes with many formats including blogs, forums, social gaming, and chat apps. Facebook, the

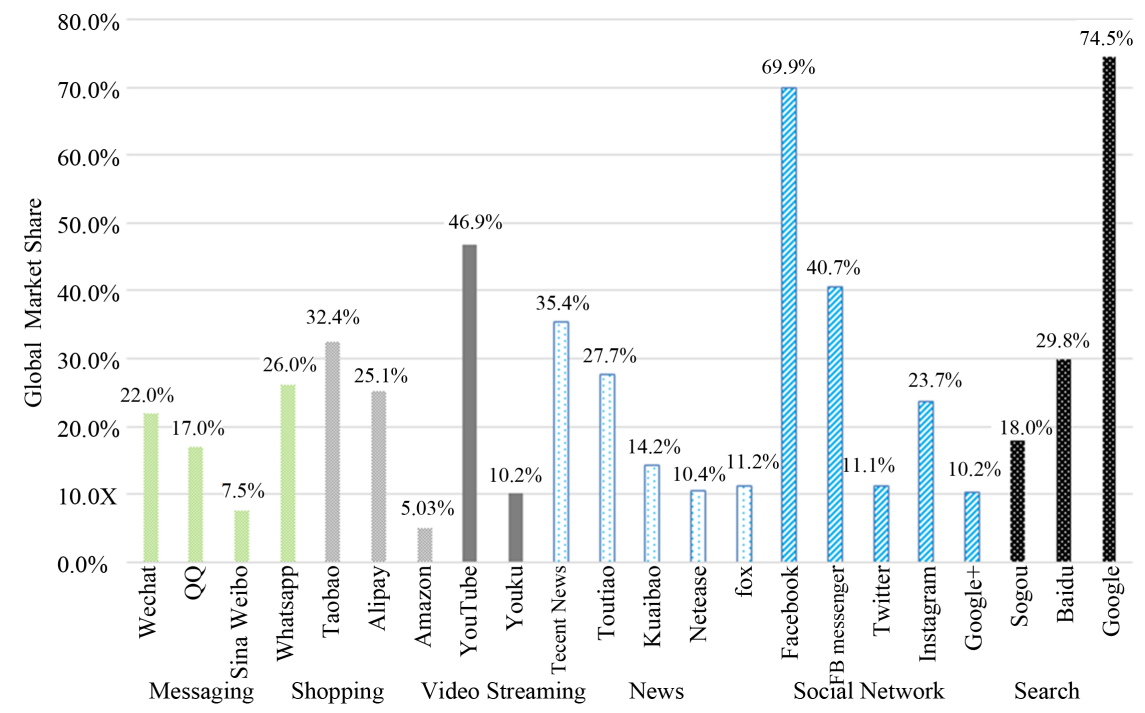

Figure 4. Market Share of Global Mobile Apps in 2017. Source: Tao [19]. 
most successful social networking platform, transferred its success from webs to mobile devices. In 2017, the Facebook app had more than 2 billion MAUs in the world with $70 \%$ market share worldwide (see Figure 4 ) and it has extended its territory to Asian markets such as Japan, Korea, and Taiwan. Facebook's $81 \%$ penetration rate among the population aged 18 and above makes it the most popular app for that age group [31]. The greatest challenge to Facebook's continued growth emanates from China where the government has strict Internet censorship that makes some new websites inaccessible and can result in app removal for existing sites. Dominant apps such as Facebook and Google are currently blocked from the largest market in the world because the Chinese government provides protection for local tech companies serving the 900 million Chinese app users.

\subsection{Search Engine Apps}

The number of search engine users in the United States has increased from 200 million in 2013 to 233 million in 2018 [32]. The greater than 16\% growth rate in 5 years demonstrates the ongoing increase in search engine use. Switching Internet searches from desktops to mobile phones signaled the forced evolution of marketing strategies. Pay-per-click (PPC) has become the most efficient and effective way for companies to invest their money in mobile marketing. Google ads are the most popular and successful PPC for targeting potential customers because PPC visitors are 50\% more likely to purchase than are organic visitors [33]. In the United States alone, there are more than 200 million mobile search apps users in 2018 to date, and the number has doubled since 2013 [17]. Google dominates the search engine markets worldwide with a net share of $74.54 \%$ (see Figure 4). However, Google has not conquered the Chinese market. Instead, Chinese search engine Baidu has approximately $70 \%$ market share in China and $30 \%$ worldwide [34] (see Figure 4).

\subsection{Mobile Shopping Apps}

Building on previous definitions, Fuentes and Svingstedt [35] define mobile shopping as a variation of shopping behavior that involves a series of mobile activities such as browsing, window-shopping, and searching for information. Mobile shopping should not be construed to have easier transaction execution than what takes place during online shopping, especially in the Chinese marketplace. Creditability, for example, could be an issue using online shopping for Chinese consumers since sellers may delay the shipping of the purchase until they receive the payment. One of the best solutions to the distrust in online payment is Alipay [36]. The Chinese mobile shopping app provides a transparent record and information for every online transaction between the buyer and seller. In 2015, there were 270 million MAUs using Alipay in China. The number grew to 450 million users in 2017 [37]. Alipay's market share of China's mobile payment reached 54\% in 2017 and Alipay world market share was $25.1 \%$ (see 
Figure 4). In the consumer-to-consumer market, Taobao has taken advantage of mobile payment, as well as $\mathrm{QR}$ codes, to make transactions easier. The online shopping website of Taobao, which is a subsidiary of the Alibaba Group, holds a $32.4 \%$ market share of global mobile apps (see Figure 4).

\subsection{Video Streaming Apps}

Figure 4 show that almost $47 \%$ of mobile apps users watch online videos using YouTube. The booming market of wireless and smartphones facilitated the development of online video platforms that provide more customized service and options, which users of mobile apps prefer. YouTube, the first and the largest online video platform in the world, has changed the way people watch videos by providing free content for everyone. With 1.5 billion people worldwide watching online videos every month, YouTube dominates the video app market and possesses the best loyalty among the app users.

Figure 5 shows the 5 -year growth rate of mobile apps since 2013. The fastest growth belongs to Amazon. The mobile shopping app has only 5\% global market share (see Figure 4) but it has grown more than 1286\% since 2013 (see Figure 5). The second fastest growth goes to Kuaibao and Toutiao with over $800 \%$ growth each since 2013. Google+ and Sogou have over 700\% growth. In the industry of video streaming apps, there is 389\% growth for YouKu and 150\% growth for YouTube. Rather than pay the fee charged by traditional channel systems, customers watch the free online video service available via YouTube. The global growth potential for online videos is excellent. In China, there were more than 100 million MAUs watching online videos in 2013 and that increased to 530 million MAUs in 2017. Chinese customers appear likely to continue using video apps given the diversity and richness of the content. Recognizing this, the top Chinese app companies such as Alibaba, Baidu, and Tencent, are attempting to extend their reach to the online video market.

Table 1 illustrates the dichotomy format used to measure the attributes of the leading mobile apps. Analysis of attributes of mobile apps show language support (translations), video streaming, and brand associations are the top factors

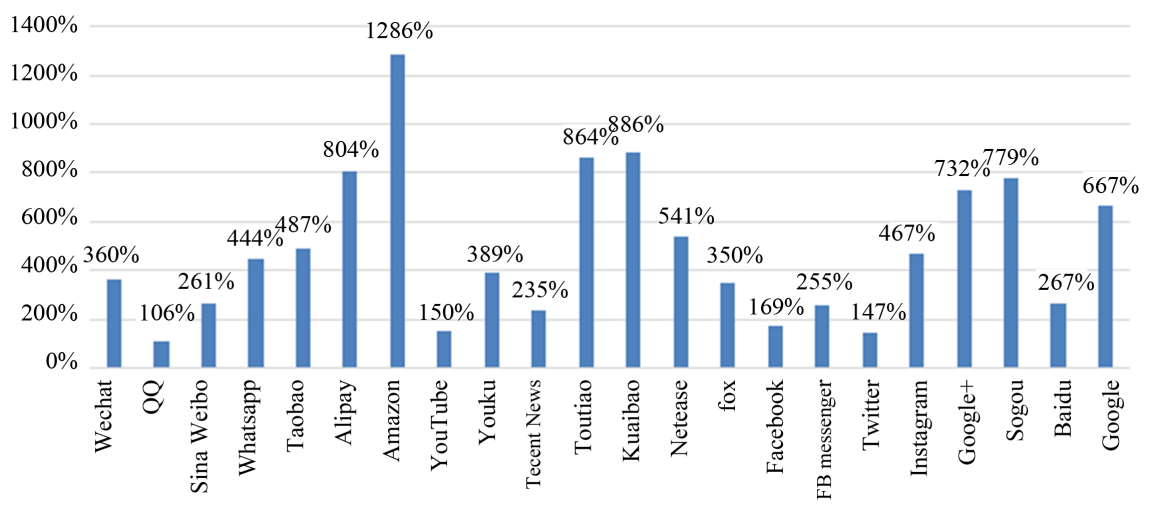

Figure 5. Market Growth Rate from 2013 to 2017. Source: Tao [19]. 
Table 1. T-test of Attributes of Mobile Apps on Market Share.

\begin{tabular}{|c|c|c|c|c|c|c|}
\hline Mobile apps & measure & sample & mean & Standard deviation & $\mathrm{t}$ value & Significance \\
\hline \multirow{3}{*}{ Ads } & Yes & 26 & 0.171 & 0.196 & \multirow{3}{*}{0.271} & \multirow{3}{*}{0.788} \\
\hline & & & & & & \\
\hline & No & 15 & 0.156 & 0.124 & & \\
\hline \multirow{3}{*}{ Gaming } & Yes & 5 & 0.337 & 0.355 & \multirow{3}{*}{10.22} & \multirow{3}{*}{0.287} \\
\hline & & & & & & \\
\hline & No & 36 & 0.141 & 0.120 & & \\
\hline \multirow{3}{*}{ Language support } & Yes & 14 & 0.257 & 0.243 & \multirow{3}{*}{20.07} & \multirow{3}{*}{0.05} \\
\hline & & & & & & \\
\hline & No & 27 & 0.118 & 0.093 & & \\
\hline \multirow[b]{2}{*}{ Video streaming } & Yes & 25 & 0.205 & 0.194 & \multirow{2}{*}{10.88} & \multirow{2}{*}{0.06} \\
\hline & No & 16 & 0.104 & 0.108 & & \\
\hline \multirow[b]{2}{*}{ Interaction } & Yes & 31 & 0.174 & 0.189 & \multirow[b]{2}{*}{0.585} & \multirow[b]{2}{*}{0.562} \\
\hline & No & 10 & 0.137 & 0.101 & & \\
\hline \multirow[b]{2}{*}{ Brand Associations } & Yes & 20 & 0.253 & 0.202 & \multirow[b]{2}{*}{30.60} & \multirow[b]{2}{*}{0.001} \\
\hline & No & 21 & 0.081 & 0.069 & & \\
\hline \multirow[b]{2}{*}{ Digital purchase } & Yes & 15 & 0.191 & 0.189 & \multirow[b]{2}{*}{0.731} & \multirow[b]{2}{*}{0.469} \\
\hline & No & 26 & 0.151 & 0.162 & & \\
\hline
\end{tabular}

determining global market share. In the study of estimating demand for mobile apps, Ghose and Han [38] examined empirical data and concluded that the demand for mobile apps derives from the users' preference for gaming apps and free apps. While gaming apps have better results, the sample size is not balanced between groups. In-app ads presence or absence has no influence on the market share. Interaction with the user has become a necessary element for most mobile apps. Digital purchase capability has better results when only select Chinese apps are examined, most likely because digital purchasing with QR code scanning is available in the Chinese market.

\section{Implications}

The use of mobile apps as a marketing tool is a necessity rather than an option because mobile app users now employ apps anytime and anywhere. In other words, businesses must pay attention to the growth of mobile apps and think about how to take advantage of the trend in the evolving competitive environment. The key to success in mobile marketing is not only acceptance of mobile apps but also the app's relevance to task completion. As shown in the results, the mobile ads do not deter customers from using apps, instead, they are an effective tool in encouraging customers to remain at the sites and click on the in-app ads. Integrating functions will be the key to the future design of mobile apps. The new design will motivate mobile apps users to make use of powerful features that enable them to find information from multiple sources, to check on the most updated news, and to change from traditional online shopping to mobile shop- 
ping [39].

\section{Conclusions}

As free mobile apps are introduced to global users, the presence of in-app ads is an inevitable requirement to offset the cost of app development [38]. The results of this study show no significant difference in market share between apps with in-app ads and those that are ad free. In-app ads may not create dissatisfied users. In fact, the increasing amount of time spent on mobile apps leads to more mobile apps employing in-app ads. Shopping mobile apps now expose users to in-app ads that allow them to access shopping information [40]. For online retailers, mobile shopping apps should be informative and make the payment process easy. Standardized digital payment processes for all shopping apps would encourage consumers to make purchases. The ease of payment available with Ali-Pay and TaoBao already brings millions of users to adopt QR code scanning and no-cash payment everywhere in China.

Brand management is a key to the success of mobile apps. As the users pay attention to the presence of multiple brands of mobile apps, app developers have the opportunity to accelerate access to new consumer markets. Facebook and Facebook Messenger, for example, are coming from the same company but they have separate apps. Both platforms have successfully created their own markets for which they provide specific services. It is very common to see multiple branding for apps in the global market. Caution should be used when applying such a strategy because there is a risk of failure due to the overlapping of apps within a brand. The majority of mobile app users ages 18 to 29 years never cease to look for sophisticated mobile apps that have more powerful and integrated functions than the previous generation of apps. However, most companies have a limited set of products available on the mobile app market and some of the apps have never been installed on smartphones. Due to the size of smartphones, their small display screens are the ultimate battlefield for mobile app occupation.

A good way to win the battle for space on the smartphone screen is developing an icon that is unique and relevant to the brand or the basic function of the app. A better design of mobile apps with a focus on creativity and recognition would make more senses to users. Users should easily recognize the icon. Future mobile apps should be easier to use, faster, and provide the services currently in demand. Language support and video streaming are strategic elements that developers need to integrate with other functions of mobile apps.

There are limitations with this study that set the stage for future research. First, the secondary data used was originally collected for a purpose other than the current research and may lack information needed because it was focused on another purpose. The sources of data from various websites may not be consistent and may require subjective judgment to minimize inconsistency.

Second, the 41 mobile apps used for this study are leaders in the global market; however, they still may not be quantitatively representative for the whole 
market. Comparisons in mobile app use between eastern countries such as China and western countries such as the United States could be better achieved if more information can be accessed.

Third, a shift in the types of mobile apps favored by users accompanied the dramatic growth rate of mobile apps made available in the past five years. The ongoing evolution of the needs and expectations of mobile app users requires continuous study to provide relevant information to marketers and app developers.

Finally, the behavior of mobile app users adapts to changing societal factors. Additionally, government restrictions have a powerful influence on behaviors. These factors call for in-depth study beyond basic human motivational drives.

\section{References}

[1] Taylor, D.G., Voelker, T.A. and Pentina, I. (2011) Mobile Application Adoption by Young Adults: A Social Network Perspective. International Journal of Mobile Marketing, 6, 60-70.

[2] Gupta, S. (2013) For Mobile Devices, Think Apps Not Ads. Harvard Business Review, 71-75.

[3] Wei, P-S. and Lu, H-P. (2014) Why Do People Play Mobile Social Games? An Examination of Network Externalities and of Uses and Gratifications. Internet Research, 24, 313-331. https://doi.org/10.1108/IntR-04-2013-0082

[4] Statista (2018) Number of Smartphone Search Users in the United States from 2013 to 2019 (in Millions).

https://www.statista.com/statistics/416391/number-smartphone-search-users-usa/

[5] Statista (2017) Percentage of U.S. Population Who Currently Use Any Social Media from 2008 to 2017.

https://www.statista.com/statistics/273476/percentage-of-us-population-with-a-soci al-network-profile/

[6] Barua, N. (2016) \#QUICKREAD: Are You Monitoring Your DAUs \& MAUs Correctly?

https://www.linkedin.com/pulse/quickread-you-monitoring-your-dau-mau-correctl y-neelanjana-barua

[7] Statista (2017) Number of Apps Available in Leading App Stores as of March 2017. https://www.statista.com/statistics/276623/number-of-apps-available-in-leading-ap p-stores/

[8] Dogtiev, A. (2018) App Download and Usage Statistics 2017. Business of Apps. http://www.businessofapps.com/data/app-statistics/

[9] Purcell, K., Entner, R. and Henderson, N. (2010) The Rise of Apps Culture. Pew Internet and American Life Project, 1-46.

[10] Chang, L. (2017) Apps Were More Popular than Ever in 2016, and It Was Largely Thanks to China. Digital Trends. https://www.digitaltrends.com/mobile/apps-grow-in-popularity-thanks-to-china/

[11] Statista (2017) Number of Mobile App Downloads Worldwide in 2016, 2017 and 2021, by Region.

https://www.statista.com/statistics/266488/forecast-of-mobile-app-downloads/

[12] App Annie (2018) China Was the Largest App Market in the World for Time Spent in Apps in 2017. App Annie. 
https://www.appannie.com/en/insights/market-data/china-app-economy-2017/

[13] Roy, S. (2017) App Adoption and Switching Behavior: Applying the Extended TAM in Smartphone App Usage. Journal of Information Systems and Technology Management, 14, 237-261. https://doi.org/10.4301/S1807-17752017000200006

[14] Perez, S. (2017) Report: Smartphone Owners Are Using 9 Apps per Day, 30 per Month.

https://techcrunch.com/2017/05/04/report-smartphone-owners-are-using-9-apps-p er-day-30-per-month/

[15] Lovejoy, B. (2017) The Average Smartphone User Spends $2 \mathrm{~h} 15 \mathrm{~m}$ a Day Using Apps-How about You? https://9to5mac.com/2017/05/05/average-app-user-per-day/

[16] Perez, S. (2017) U.S. Consumers Now Spend 5 Hours Per Day on Mobile Devices. https://techcrunch.com/2017/03/03/u-s-consumers-now-spend-5-hours-per-day-on -mobile-devices

[17] Statista (2018) Global Digital Population as of January 2018. https://www.statista.com/statistics/617136/digital-population-worldwide

[18] Hollander, R. (2018) Consumers in China Are Spending the Most Time in Apps. http://www.businessinsider.com/consumers-in-china-are-spending-the-most-time-i n-apps-2018-2

[19] Tao, K. (2018) Compilation of Data from International Third-Party Websites and Reports, Including Online Statistics, Market Research, Business Intelligence, and Journal Publications Dated from 2013 to 2017.

[20] Sterling, G. (2015) Report: Mobile Users Spend 80 Percent of Time in Just Five Apps.

https://marketingland.com/report-mobile-users-spend-80-percent-time-just-five-ap ps-116858

[21] Gurtner, S., Reinhardt, R. and Soyez, K. (2014) Designing Mobile Business Applications for Different Age Groups. Technological Forecasting and Social Change, 88, 177-188. https://doi.org/10.1016/j.techfore.2014.06.020

[22] Statista (2018) Cumulative Number of Apps Downloaded from the Apple App Store from July 2008 to June 2017 (in Billions).

https://www.statista.com/statistics/263794/number-of-downloads-from-the-apple-a pp-store

[23] Harris, M.A. and Chin, A.G. (2016) Consumer Trust in Google's Top Developers' Apps: An Exploratory Study. Information and Computer Security, 24, 474-495. https://doi.org/10.1108/ICS-11-2015-0044

[24] Kulemeka, O. (2015) A Review of Wildland Fire Smartphone Applications: A Classification Study from Australia, USA, Canada and South Africa. Internal Journal of Emergency Services, 4, 258-270. https://doi.org/10.1108/IJES-07-2014-0010

[25] Pon, B., Seppälä, T. and Kenney, M. (2015) One Ring to Unite Them All: Convergence, the Smartphone, and the Cloud. Journal of Industry, Competition and Trade, 15, 21-33. https://doi.org/10.1007/s10842-014-0189-x

[26] Son, J. (2017) The Impact of Initial Experience and User Attachment on Application Downloads: Information-Seeking and -Sharing Applications. Internet Research, 27, 256-276. https://doi.org/10.1108/IntR-03-2015-0062

[27] Lella, A. and Lipsman, A. (2017) The 2017 U.S. Mobile App Report. https://www.comscore.com/Insights/Presentations-and-Whitepapers/2017/The-201 7-US-Mobile-App-Report

[28] App Annie (2017) App Annie Launches China Android Metrics. 
https://www.appannie.com/cn/insights/app-annie-news/app-annie-launches-chinaandroid-metrics

[29] Sampi (2017) Top 10 Most Popular Mobile Apps in China. https://sampi.co/top-10-most-popular-mobile-apps-in-china

[30] Sevitt, D. (2017) The Most Popular Messaging Apps by Country. https://www.similarweb.com/blog/popular-messaging-apps-by-country

[31] Lipsman, A. (2017) 5 Interesting Facts about Millennials' Mobile App Usage from “The 2017 U.S. Mobile App Report”. https://www.comscore.com/Insights/Blog/5-Interesting-Facts-About-Millennials-M obile-App-Usage-from-The-2017-US-Mobile-App-Report

[32] Statista (2018) Number of Search Engine Users in the United States from 2014 to 2020 (in Millions).

https://www.statista.com/statistics/253795/number-of-search-engine-users-in-the-u nited-states

[33] Gardner, O. (2012) SEO vs PPC-Time for a Fight!

https://unbounce.com/ppc/seo-vs-ppc-infographic

[34] DMR (2018) 85 Amazing Baidu Statistics and Facts. https://expandedramblings.com/index.php/baidu-stats

[35] Fuentes, C. and Svingstedt, A. (2017) Mobile Phones and the Practice of Shopping: A Study of How Young Adults Use Smartphones to Shop. Journal of Retailing and Consumer Services, 38, 137-146. https://doi.org/10.1016/j.jretconser.2017.06.002

[36] Chen, Y.-M., Hsu, T.-H. and Lu, Y.-J. (2018) Impact of Flow on Mobile Shopping Intention. Journal of Retailing and Consumer Services, 41, 281-287. https://doi.org/10.1016/j.jretconser.2017.04.004

[37] Smith, C. (2018) 32 Amazing Alipay Statistics and Facts. https://expandedramblings.com/index.php/alipay-statistics

[38] Ghose, A. and Han, S.P. (2014) Estimating Demand for Mobile Applications in the New Mobile Economy. Management Science, 60, 1470-1488. https://doi.org/10.1287/mnsc.2014.1945

[39] Rigby, D. (2011) The Future of Shopping. https://hbr.org/2011/12/the-future-of-shopping

[40] Nielsen (2016) The Where Behind The Wear: Americans Are Buying Clothes In-Store, Online and on Their Phones.

http://www.nielsen.com/us/en/insights/news/2016/the-where-behind-the-wear-ame ricans-buy-clothes-in-store-online-on-phones.html 